\title{
Relationship of ideal cardiovascular health metrics with retinal vessel calibers and retinal nerve fiber layer thickness: a cross- sectional study
}

Qian Zhang ${ }^{1,2,3,4}$, Dandan Wang ${ }^{1,2,3,4}$, Anxin Wang ${ }^{1,2,3,4}$, Shufeng Zhang ${ }^{5}$, Yuesong Pan ${ }^{1,2,3,4}$, Yang Li ${ }^{6}$, Shengyun Chen ${ }^{1,2,3,4}$, Shouling $\mathrm{Wu}^{7^{*}}$, Wenbin Wei ${ }^{6^{*}}$ and Xingquan Zhao ${ }^{1,2,3,4^{*}}$

\begin{abstract}
Background: Ideal cardiovascular health (CVH) metrics have been found to be associated with subclinical vascular abnormalities. However, the relationship between ideal CVH metrics and retinal vessel calibers and retinal nerve fiber layer (RNFL) thickness in a Chinese population is unknown.

Methods: We collected information on the seven ideal CVH metrics among 3376 participants aged 40 years or older from the Asymptomatic Polyvascular Abnormalities Community Study in 2012. Retinal vessel calibers and RNFL thickness were assessed by retinal photography and spectral-domain optical coherence tomography. Multivariable linear models were used to analyze the relationship between ideal CVH metrics and retinal parameters.

Results: With the decreased number of ideal $\mathrm{CVH}$ metrics, central retinal arteriolar equivalents (CRAE) was significantly narrowed and arterio- venous ratio (AVR) significantly decreased $(p<0.0001)$. While the RNFL thickness and central retinal venous equivalents (CRVE) showed no significant changes with the decreased ideal CVH metrics. Linear regression showed that both CRAE and AVR was positively related with the number of ideal CVH metrics (regression coefficient beta: 0.806 , 95\% confidence interval (Cl): 0.266-1.346 for CRAE (micron); and regression coefficient beta: 0 . 005, 95\% Cl: 0.002-0.009 for AVR) after adjusting for age (year), sex= male (n), education (n), average monthly income ( $¥)$ and other related risk factors.

Conclusions: These findings suggested a clear positive relationship between the number of ideal CVH metrics and CRAE and AVR in Chinese population, supporting the importance of ideal health behaviors and factors in subclinical vascular abnormalities prevention.
\end{abstract}

Keywords: Ideal cardiovascular health metrics, Retinal vessel calibers, Retinal nerve fiber layer thickness

\footnotetext{
*Correspondence: drwus|@163.com; tr_weiwenbin@163.com; zxq@vip.163.com

${ }^{7}$ Department of Cardiology, Kailuan Hospital, Tangshan 063000, China

${ }^{6}$ Beijing Tongren Eye Center, Beijing Key Laboratory of Ophthalmology and Visual Science, Beijing Tongren Hospital, Capital Medical University, 1 Dong Jiao Min Lane, Beijing 100730, China

'Department of Neurology, Beijing Tiantan Hospital, Capital Medical University,

No.6 Tiantanxili, Dongcheng District, Beijing 100050, China

Full list of author information is available at the end of the article
}

(c) The Author(s). 2018 Open Access This article is distributed under the terms of the Creative Commons Attribution 4.0 International License (http://creativecommons.org/licenses/by/4.0/), which permits unrestricted use, distribution, and reproduction in any medium, provided you give appropriate credit to the original author(s) and the source, provide a link to the Creative Commons license, and indicate if changes were made. The Creative Commons Public Domain Dedication waiver (http://creativecommons.org/publicdomain/zero/1.0/) applies to the data made available in this article, unless otherwise stated. 


\section{Background}

In 2010, the American Heart Association (AHA) has proposed the concept of "ideal cardiovascular health $(\mathrm{CVH})$ ", which is defined as the simultaneous presence of 4 ideal health behaviors [nonsmoking, body mass index $(\mathrm{BMI})<25 \mathrm{~kg} / \mathrm{m}^{2}$, physical activity at goal levels, and a diet consistent with current guideline recommendations], and 3 ideal health factors [untreated total cholesterol $<200 \mathrm{mg} / \mathrm{dl}$, untreated systolic blood pressure $(\mathrm{SBP})<120 \mathrm{mmHg}$ and diastolic blood pressure $(\mathrm{DBP})<$ $80 \mathrm{mmHg}$, and untreated fasting blood glucose < $100 \mathrm{mg} / \mathrm{dl}$ ] [1]. The main aim of $\mathrm{CVH}$ is to improve the cardiovascular health by $20 \%$ while reducing deaths from cardiovascular diseases and stroke by $20 \%$ by 2020 . This "primordial prevention" refers to preventing the initial occurrence of risk factors by adopting healthier behaviors, rather than preventing the development of a given disease, which is distinctly different from "primary prevention" [2]. Several previous studies have demonstrated a low prevalence of these ideal $\mathrm{CVH}$ metrics in general population and a significant inverse relationship between the number of ideal $\mathrm{CVH}$ metrics and the incidence of cardiovascular diseases (CVD) [3-6]. Our previous study evidences showed a similar association with CVD and stroke risk in a Chinese population [7, 8]. Ideal $\mathrm{CVH}$ metrics were also found to be associated with carotid intima-media thickness (CIMT) [9] and carotid plaque [10], intima media thickness (IMT), and elasticity of the abdominal aorta [11], and arterial stiffness [12]. Similar results were put forwarded by our previous study regarding the association between ideal $\mathrm{CVH}$ metrics and intracranial artery stenosis (ICAS) [13] and extracranial artery stenosis (ECAS) [14].Considering atherosclerosis as a diffuse and systemic disease, ideal $\mathrm{CVH}$ metrics may induce an effect on retinal vessels. Ogagarue et al. found that poor ideal $\mathrm{CVH}$ metrics were associated with wider retinal venules and narrower retinal arterioles [15]. Our previous study showed that the localized retinal nerve fiber layer (RNFL) defects were associated with previous or acute stroke [16]. We therefore examined if ideal $\mathrm{CVH}$ parameters were associated with central retinal arteriolar equivalents (CRAE), central retinal venous equivalents (CRVE), arterio-venous ratio (AVR) and RNFL thickness in Chinese community population.

\section{Methods}

The Asymptomatic Polyvascular Abnormalities Community study (APAC) [17] is a community-based, prospective study to investigate the epidemiology of asymptomatic polyvascular abnormalities in Chinese adults. From June 2010 to June 2011, a total of 5440 subjects were randomly sampled from Kailuan study [7, 8, 18, 19]. A population from the previously described study who completed the baseline survey was recruited in the APAC study.
The inclusion criteria were as follows: (1) aged 40 years or older; and (2) free of stroke, transient ischemic attack, and coronary disease. All the participants had undergone questionnaire assessment, clinical, laboratory, transcranial Doppler (TCD), and duplex sonography examinations during the baseline survey. During the follow-up in 2012, 3376 participants underwent examination of retinal photography and spectral-domain optical coherence tomography (SD-OCT). Data on questionnaire assessment, clinical, and laboratory examinations were also collected repeatedly like baseline examinations. The APAC study was performed according to the guidelines of Helsinki Declaration and was approved by both the Ethics Committees of the Kailuan General Hospital and Beijing Tiantan Hospital. Written informed consent was obtained from all participants and approved by the above ethics committees.

Detailed definition of ideal $\mathrm{CVH}$ metrics has been described before $[8,13]$. Ideal smoking status was defined as having never smoked. Ideal dietary data, which was mainly based on salt intake, were defined as a consumption of $<6 \mathrm{~g} /$ day. Ideal physical activity was defined as moderate or vigorous physical activity for $\geq 80 \mathrm{~min}$ per week. BMI was defined as ideal if it was $<25 \mathrm{~kg} / \mathrm{m}^{2}$. Blood pressure was defined as ideal if SBP was < $120 \mathrm{mmHg}$ and DBP was $<80 \mathrm{mmHg}$, without the use of antihypertensives. Fasting blood glucose was defined as ideal if $<100 \mathrm{mg} / \mathrm{dL}$ and if untreated. Total cholesterol was defined as ideal if the untreated total cholesterol level was $<200 \mathrm{mg} / \mathrm{dL}$.

Hypertension was defined as the presence of a history of hypertension, or using antihypertensive medication, or a SBP $\geq 140 \mathrm{mmHg}$, or a DBP $\geq 90 \mathrm{mmHg}$ at baseline. Diabetes mellitus was defined as a self-reported history, currently treated with insulin or oral hypoglycemic agents, or fasting blood glucose level $\geq 126 \mathrm{mg} / \mathrm{dl}$. Hyperlipidemia was defined as a self-reported history, current use of cholesterol lowering medicine, or total cholesterol level $\geq 220 \mathrm{mg} / \mathrm{dl}$ or triglyceride $\geq 150 \mathrm{mg} / \mathrm{dl}$.

All the study participants underwent fundus photography to measure the retinal arteriolar and venular calibers and OCT to measure the thickness of RNFL. We used a non-mydriatic digital fundus camera (fundus camera Type CR6-45NM; Canon, Ōta, Tokyo, Japan) to take the fundus photography and the vascular calibers were measured using computer assisted quantitative assessment software (IVAN; University of Wisconsin, Madison, WI). Average CRAE and CRVE were calculated by using the Parr-Hubbard formula and were presented as CRAE or CRVE equivalent. The AVR was calculated as CRAE/CRVE.

Spectral-domain OCT images were collected from the optic nerve head, macula and adjacent retina through non-dilated pupils in a sitting position (iVue SD-OCT, 
Optovue Inc., Fremont, California, USA). The iVue SD-OCT used a super luminescent diode scan with a center wavelength of $840 \pm 10 \mathrm{~nm}$ to provide high resolution images. A $6 \times 6 \mathrm{~mm}^{2}$ raster scan was centered on the optic disc and macula.. We performed quality assurance checks. Images with failed segmentation of the RNFL, motion artifacts, poor focusing, a scan score index $<40$ and images not centered on the optic disc were excluded from the assessment. Two experienced examiners scanned all study participants. Although both eyes of each study participant were detected, we used one eye's (right eye first, if not available, we used left eye instead) mean peripapillary RNFL thickness from each participant for further analysis. Corneal curvature and spherical equivalent were adjusted when analyzing the data with ideal $\mathrm{CVH}$.

Statistical analyses were performed using the SAS software (version 9.3; SAS Institute, Cary, North Carolina, USA). Continuous variables were described by means ( \pm standard deviation) and categorical variables were described as percentages. Continuous variables including age, BMI, RNFL thickness, CRAE, CRVE and AVR were compared using analysis of variance, and categorical variables including sex, previous history of hypertension, diabetes and hyperlipidemia, family history of stroke and smoking were compared using chi-squared test in the basic characteristics comparisons. To avoid bias, we compared the key risk factors in those included population whose data were complete versus those excluded from the analyses whose data were incomplete, as shown in Table 1. Then we used a multivariable linear model to analyze the associations of CRAE and AVR with the number of ideal $\mathrm{CVH}$ metrics, adjusted for age (year), sex = male (n), education (n), average monthly income of every family member $(¥)$ and family history of stroke (n).
We adjusted variables of age, sex, education, income and family history because they are risk factors for retinal vessel parameters, and were associated with number of ideal $\mathrm{CVH}$ metrics. We also tested the interactions with age ( $<60$ years versus $\geq 60$ years) and sex. All statistical tests were 2-sided, and a significant level was set as 0.05 .

\section{Results}

We excluded 217 participants who had incomplete data on health factors or behaviors, and who had incomplete information on retinal parameters, leaving 1793 men and 1366 women for analyses in this study. The basic characteristics between the included and excluded participants were presented in Table 1 . The inclusive participants were younger and had a thicker RNFL thickness. The other metrics such as gender, smoking, BMI and previous history of diseases showed no differences between the groups.

Table 2 showed the basic characteristics of participants regarding the number of ideal CVH metrics in 2012. There were significant differences in age, gender, education, and income level in participants with different number of ideal $\mathrm{CVH}$ metrics $(p<0.05)$.We did not observe any significant differences in the family history of stroke between different numbers of ideal $\mathrm{CVH}$ metrics $(P=0.77)$. Participants with a smaller number of ideal $\mathrm{CVH}$ metrics were more likely to have a previous history of diabetes, hypertension, or dyslipidemia.

As the number of ideal $\mathrm{CVH}$ metrics decreased, the CRAE became obviously narrower and AVR obviously decreased $(p<0.0001)$. While the RNFL thickness and CRVE showed no significant changes with the decreased number of ideal $\mathrm{CVH}$ metrics $(P=0.81$ and 0.13 , respectively), (Table 3).

Table 1 Comparison of basic characteristics between inclusive and exclusive participants

\begin{tabular}{|c|c|c|c|c|}
\hline & Entire participants (3376) & Subjects included $(n=3159)$ & Subjects excluded $(n=217)$ & $P$ value \\
\hline Male (n, \%) & $1918(56.81 \%)$ & $1793(56.76 \%)$ & $125(57.60 \%)$ & 0.83 \\
\hline Age, y $($ mean $\pm S D)$ & $56.67 \pm 10.33$ & $56.17 \pm 9.88$ & $64.05 \pm 13.48$ & $<0.0001$ \\
\hline \multicolumn{5}{|l|}{ Previous history of disease } \\
\hline hypertension(n, \%) & 1178 (34.89\%) & $1094(34.63 \%)$ & $84(38.71 \%)$ & 0.24 \\
\hline diabetes(n, \%) & $352(10.43 \%)$ & $321(10.16 \%)$ & $31(14.29 \%)$ & 0.07 \\
\hline hyperlipidemia(n, \%) & $566(16.77 \%)$ & $525(16.62 \%)$ & $41(18.89 \%)$ & 0.40 \\
\hline Family history of stroke $(n, \%)$ & $82(2.43 \%)$ & $81(2.56 \%)$ & $1(0.46 \%)$ & 0.0627 \\
\hline Smoking(n, \%) & $666(19.73 \%)$ & $634(20.07 \%)$ & $32(14.75 \%)$ & 0.0636 \\
\hline $\mathrm{BMl}, \mathrm{kg} / \mathrm{m}^{2}($ mean $\pm \mathrm{SD})$ & $24.93 \pm 3.25$ & $24.93 \pm 3.22$ & $24.93 \pm 3.65$ & 0.83 \\
\hline RNFL thickness, micron (mean \pm SD) & $101.89 \pm 10.53$ & $102.14 \pm 10.37$ & $98.16 \pm 12.01$ & $<0.0001$ \\
\hline CRAE, micron (mean $\pm S D$ ) & & $153.87 \pm 19.72$ & & \\
\hline CRVE, micron (mean $\pm S D$ ) & & $232.73 \pm 25.75$ & & \\
\hline $\mathrm{AVR}($ mean $\pm \mathrm{SD})$ & & $0.67 \pm 0.11$ & & \\
\hline
\end{tabular}


Table 2 Basic characteristics of participants regarding the number of ideal cardiovascular health metrics in 2012

\begin{tabular}{|c|c|c|c|c|c|c|c|c|c|}
\hline & \multicolumn{7}{|c|}{ Number of ideal cardiovascular health metrics } & \multirow[t]{2}{*}{$p$ value } & \multirow[t]{2}{*}{$p$ trend } \\
\hline & 0 & 1 & 2 & 3 & 4 & 5 & 6 or 7 & & \\
\hline Total(n) & 94 & 393 & 803 & 878 & 642 & 278 & 71 & & \\
\hline Women $(\%, n)$ & $6.4(6)$ & $26.0(102)$ & $34.6(278)$ & $44.7(392)$ & $55.0(353)$ & $66.2(184)$ & $71.8(51)$ & $<0.0001$ & $<0.0001$ \\
\hline Age, y $($ mean $\pm S D)$ & $55.3 \pm 6.9$ & $56.4 \pm 8.7$ & $56.6 \pm 9.2$ & $56.3 \pm 10.4$ & $56.0 \pm 10.4$ & $55.3 \pm 11.3$ & $54.7 \pm 9.2$ & 0.0023 & 0.12 \\
\hline \multicolumn{10}{|l|}{ Previous history of disease } \\
\hline Diabetes $(\%, n)$ & $29.8(28)$ & $22.4(88)$ & $14.5(116)$ & $5.9(52)$ & $5.3(34)$ & $1.1(3)$ & 0 & $<0.0001$ & $<0.0001$ \\
\hline Hypertension $(\%, n)$ & $55.3(52)$ & $54.5(214)$ & $42.7(343)$ & $33.5(294)$ & $23.2(149)$ & $12.6(35)$ & $9.9(7)$ & $<0.0001$ & $<0.0001$ \\
\hline Dyslipidemia $(\%, n)$ & $35.1(33)$ & $30.8(121)$ & $21.5(173)$ & $14.5(127)$ & $7.8(50)$ & $6.5(18)$ & $4.2(3)$ & $<0.0001$ & $<0.0001$ \\
\hline Family history of stroke $(\%, n)$ & $4.3(4)$ & $2.8(11)$ & $4.0(32)$ & $3.1(27)$ & $3.6(23)$ & $2.2(6)$ & $4.2(3)$ & 0.77 & 0.62 \\
\hline education $(\%, n)$ & & & & & & & & $<0.0001$ & $<0.0001$ \\
\hline High school or college & $3.4(29)$ & $11.4(97)$ & $22.0(187)$ & $30.9(263)$ & $22.4(190)$ & $7.9(67)$ & $2.0(17)$ & & \\
\hline Middle school & $3.0(50)$ & $15.0(251)$ & $30.0(495)$ & $27.9(465)$ & $17.2(287)$ & $6.2(103)$ & $1.1(18)$ & & \\
\hline Illiteracy/Primary & $2.3(15)$ & $7.0(45)$ & $18.9(121)$ & $23.4(150)$ & $25.8(165)$ & 16.9 (108) & $5.6(36)$ & & \\
\hline $\begin{array}{l}\text { average monthly income of } \\
\text { every family member (¥) }\end{array}$ & & & & & & & & $<0.0001$ & 0.47 \\
\hline$>3000$ & $3.5(22)$ & $11.6(73)$ & $25.4(159)$ & $28.4(178)$ & $21.1(132)$ & $7.7(48)$ & $2.4(15)$ & & \\
\hline $1000-3000$ & $2.7(44)$ & $12.5(201)$ & $25.2(405)$ & $26.9(433)$ & $20.9(336)$ & 9.5 (153) & $2.3(37)$ & & \\
\hline$<1000$ & $3.0(28)$ & 12.9 (119) & 25.9 (239) & $28.9(267)$ & $18.9(174)$ & $8.3(77)$ & $2.1(19)$ & & \\
\hline
\end{tabular}

$S D$ standard deviation

We further used multivariable linear models to analyze the relationship between ideal CVH metrics and CRAE. Mean CRAE showed a positive relation with the number of ideal $\mathrm{CVH}$ metrics in the liner regression after adjusting for age (year), sex = male $(n)$, education $(n)$, average monthly income $(¥)$ and other related risk factors. The results revealed for every one unit increase of the number of ideal $\mathrm{CVH}$ metrics, the diameter of CRAE increases by $0.806 \mu \mathrm{m}$. For the other variables, when the sex changes from female to male and age increases by 1 year, then the diameter of the CRAE diminishes $4.119 \mu \mathrm{m}$ and $0.384 \mu \mathrm{m}$, respectively. After dividing the study group by age (year) and sex = male (n), we found a significant relationship in age $<60 \mathrm{y}$ subgroup and women subgroup ( $P=0.0002$ and 0.0080 , respectively). However, we did not observe a significant interaction between the number of ideal health metrics and age or sex in relation to CRAE $(P>0.05$ for both interactions), (Table 4).

Next, the relationship between AVR and the number of ideal $\mathrm{CVH}$ metrics in a linear regression adjusted by age (year), sex = male $(n)$, education $(n)$, average monthly income (¥), and family history of stroke (n) was assessed. We also found a positive relation with AVR and the number of ideal $\mathrm{CVH}$ metrics. Also when the number of ideal CVH metrics increases by every one unit, the AVR increases by 0.005 . For the other variables, when the sex changes from female to male, the AVR diminishes 0.020 . While when age increases by 1 year, there is no significant change in AVR. When dividing the groups by sex = male (n) and age (year), the relationship in age $<60 \mathrm{y}$ subgroup was more obvious than age $>60$ y subgroup,

Table 3 Mean Retinal Nerve Fiber Layer (RNFL) thickness and vessel calibers in participants with different number of ideal cardiovascular health metrics

\begin{tabular}{|c|c|c|c|c|c|c|c|c|c|}
\hline & \multicolumn{7}{|c|}{ Number of ideal cardiovascular health metrics } & \multirow[t]{2}{*}{$p$ value } & \multirow[t]{2}{*}{$p$ trend } \\
\hline & $\overline{0}$ & 1 & 2 & 3 & 4 & 5 & 6 or 7 & & \\
\hline $\begin{array}{l}\text { RNFL thickness, } \\
\text { micron(mean } \pm S D)\end{array}$ & $103.03 \pm 9.76$ & $102.00 \pm 10.70$ & $101.90 \pm 9.76$ & $102.36 \pm 10.95$ & $102.11 \pm 9.86$ & $102.11 \pm 11.24$ & $102.31 \pm 10.02$ & 0.81 & 0.94 \\
\hline $\begin{array}{l}\text { CRAE, } \\
\text { micron(mean } \pm S D)\end{array}$ & $153.76 \pm 22.02$ & $150.45 \pm 18.94$ & $153.41 \pm 19.00$ & $153.23 \pm 20.33$ & $155.05 \pm 19.59$ & $157.85 \pm 19.67$ & $159.81 \pm 18.77$ & $<0.0001$ & $<0.0001$ \\
\hline $\begin{array}{l}\text { CRVE, } \\
\text { micron(mean } \pm S D)\end{array}$ & $241.05 \pm 26.69$ & $234.07 \pm 25.05$ & $232.12 \pm 26.21$ & $232.29 \pm 25.86$ & $232.47 \pm 24.37$ & $232.01 \pm 27.18$ & $231.97 \pm 26.90$ & 0.13 & 0.058 \\
\hline AVR(mean $\pm S D)$ & $0.64 \pm 0.10$ & $0.65 \pm 0.10$ & $0.67 \pm 0.11$ & $0.67 \pm 0.12$ & $0.67 \pm 0.10$ & $0.69 \pm 0.12$ & $0.70 \pm 0.10$ & $<0.0001$ & $<0.0001$ \\
\hline
\end{tabular}


Table $4 \beta$ Coefficients (and 95\%confidence intervals) from linear models for the relationship between central retinal arteriolar equivalents and the number of ideal cardiovascular health metrics

\begin{tabular}{|c|c|c|c|c|c|}
\hline & VIF & $\beta$ & $95 \% \mathrm{Cl}$ of $\beta$ & $p$ value & $p$ interaction \\
\hline Total & & 175.908 & $170.085-181.732$ & $<0.0001$ & \\
\hline Number of ideal CVH metrics ( $n$ ) & 1.220 & 0.806 & $0.266-1.346$ & 0.0035 & \\
\hline sex $=$ male $(n)$ & 1.249 & -4.119 & $-5.570--2.669$ & $<0.0001$ & \\
\hline age (year) & 1.100 & -0.384 & $-0.455--0.313$ & $<0.0001$ & \\
\hline education (n) & 1.096 & & & & \\
\hline High school or college & & - & - & - & \\
\hline Middle school & & 1.426 & $-0.196-3.048$ & 0.08 & \\
\hline Illiteracy/Primary & & 1.702 & $-0.396-3.799$ & 0.11 & \\
\hline $\begin{array}{l}\text { average monthly income of every } \\
\text { family member ( } ¥)\end{array}$ & 1.051 & & & & \\
\hline$>3000$ & & - & - & - & \\
\hline $1000-3000$ & & -0.121 & $-1.934-1.693$ & 0.90 & \\
\hline$<1000$ & & -0.648 & $-2.648-1.351$ & 0.53 & \\
\hline family history of stroke (n) & 1.005 & -1.325 & $-5.058-2.408$ & 0.49 & \\
\hline Age (year) & & & & & 0.0656 \\
\hline \multicolumn{6}{|l|}{$<60 y^{a}$} \\
\hline Number of ideal $\mathrm{CVH}$ metrics & 1.275 & 1.185 & $0.558-1.812$ & 0.0002 & \\
\hline \multicolumn{6}{|l|}{$\geq 60 y^{a}$} \\
\hline Number of ideal $\mathrm{CVH}$ metrics & 1.146 & 0.243 & $-0.885-1.371$ & 0.67 & \\
\hline $\operatorname{Sex}(n)$ & & & & & 0.36 \\
\hline \multicolumn{6}{|l|}{ Men $^{b}$} \\
\hline Number of ideal CVH metrics & 1.062 & 0.694 & $-0.048-1.436$ & 0.07 & \\
\hline \multicolumn{6}{|l|}{ Women $^{\mathrm{b}}$} \\
\hline Number of ideal $\mathrm{CVH}$ metrics & 1.018 & 1.089 & $0.285-1.894$ & 0.0080 & \\
\hline
\end{tabular}

$\mathrm{Cl}$ confidence interval

VIF Variance Inflation Factor

All the coefficients without footnotes in total part are adjusted by other variates in total part when presented

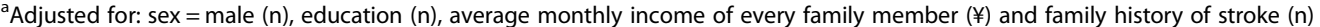

${ }^{b}$ Adjusted for: age(year),education (n), average monthly income of every family member ( $\left.¥\right)$ and family history of stroke (n)

and was more obvious in women group than in men subgroup, though both showed a significant meaning $(P<0.05)$, (Table 5). However, we did not observe a significant interaction between the number of ideal health metrics and age or sex in relation to AVR $(P>0.05$ for both interactions).

\section{Discussion}

Our study participants with larger number of ideal $\mathrm{CVH}$ metrics had a significantly wider CRAE and a larger AVR in univariate analysis and in multivariable linear regression adjusted for parameters such as sex, age, education, average monthly income of every family member, and family history of stroke.

As reported before, the ideal $\mathrm{CVH}$ metrics are strongly associated with the risk of stroke [8]. There are already some positive conclusions from other research studies regarding the relation between cerebrovascular diseases and retinal abnormalities. Data from the Beaver Dam
Eye Study showed that the retinal abnormalities, such as arteriolar narrowing, were associated with long- term cardiovascular (including stroke) mortality, especially in younger people [20, 21]. The Cooper and Lindley's study showed that these retinal caliber changes were all related with MRI-defined subclinical cerebral infarcts and lacunar infarctions [22, 23]. Data from the Rotterdam Scan Study showed that the retinal venular dilation was related to the progression of cerebral small vessel disease [24]. RNFL is one of the most important retinal layers and is very sensitive to the abnormal tiny blood circulation. Our previous study has demonstrated that no matter whether acute or previous stroke were both significantly associated with the thinning of RNFL [16]. Investigation by Kim and his associates on 4395 Korean individuals showed that the higher prevalence of thinning of the RNFL was significantly correlated with cerebral small vessel diseases as detected by magnetic resonance imaging [25]. Thus, our study focused on the 
Table 5 Coefficients (and 95\%confidence intervals) from linear models for the relationship between arterio-venous ratio and the number of ideal cardiovascular health metrics

\begin{tabular}{|c|c|c|c|c|c|}
\hline & VIF & $\beta$ & $95 \% \mathrm{Cl}$ of $\beta$ & $p$ value & $p$ interaction \\
\hline Total & & 0.654 & $0.620-0.687$ & $<0.0001$ & \\
\hline Number of ideal $\mathrm{CVH}$ metrics & 1.220 & 0.005 & $0.002-0.009$ & 0.0006 & \\
\hline sex $=$ male $(n)$ & 1.249 & -0.020 & $-0.029--0.012$ & $<0.0001$ & \\
\hline age (year) & 1.100 & $<0.001$ & $-0.0003-0.0005$ & 0.71 & \\
\hline education (n) & 1.096 & & & & \\
\hline High school or college & & - & - & - & \\
\hline Middle school & & 0.004 & $-0.006-0.013$ & 0.42 & \\
\hline Illiteracy/Primary & & 0.002 & $-0.010-0.014$ & 0.79 & \\
\hline $\begin{array}{l}\text { average monthly income of every } \\
\text { family member ( } ¥)\end{array}$ & 1.051 & & & & \\
\hline$>3000$ & & - & - & - & \\
\hline$¥ 1000-3000$ & & 0.005 & $-0.005-0.015$ & 0.34 & \\
\hline$<¥ 1000$ & & 0.001 & $-0.010-0.013$ & 0.84 & \\
\hline family history of stroke (n) & 1.005 & 0.001 & $-0.021-0.022$ & 0.94 & \\
\hline Age (year) & & & & & 0.12 \\
\hline \multicolumn{6}{|l|}{$<60 y^{a}$} \\
\hline Number of ideal CVH metrics & 1.275 & 0.007 & $0.004-0.011$ & $<0.0001$ & \\
\hline \multicolumn{6}{|l|}{$\geq 60 y^{a}$} \\
\hline Number of ideal $\mathrm{CVH}$ metrics & 1.146 & $<0.001$ & $-0.007-0.007$ & 0.98 & \\
\hline Sex $(n)$ & & & & & 0.65 \\
\hline \multicolumn{6}{|l|}{ Men ${ }^{b}$} \\
\hline Number of ideal CVH metrics & 1.062 & 0.005 & $0.0002-0.0092$ & 0.04 & \\
\hline \multicolumn{6}{|l|}{ Women ${ }^{b}$} \\
\hline Number of ideal CVH metrics & 1.018 & 0.007 & $0.003-0.011$ & 0.0015 & \\
\hline
\end{tabular}

Cl confidence interval

VIF Variance Inflation Factor

All the coefficients without footnotes in total part are adjusted by other variates in total part when presented

adjusted for: sex = male (n), education (n), average monthly income of every family member (¥) and family history of stroke (n)

${ }^{b}$ Adjusted for: age(year),education (n), average monthly income of every family member ( $\left.¥\right)$ and family history of stroke (n)

association between ideal $\mathrm{CVH}$ metrics and retinal abnormalities, including retinal microvascular caliber changes and retinal nerve fiber layer defects.

Ideal $\mathrm{CVH}$ metrics have been found to be associated with subclinical vascular abnormalities [26], including subclinical markers of carotid structure and function, such as CIMT and carotid plaque [9, 10], IMT and elasticity of the abdominal aorta [11], and arterial stiffness [12]. Our previous studies showed the association between ideal CVH metrics and ICAS [13] and ECAS [14]. Our study also showed that the thinner retinal artery diameter was significantly associated with increased common carotid artery IMT [27]. Previous investigations showed correlations between the retinal microvasculature, RNFL thickness and arterial hypertension, as well as high plasma glucose, high blood lipids and smoking $[15,28-34]$, all of which are components of AHA CVH metrics. Our study showed that the CRAE was decreased significantly with a smaller number of ideal
$\mathrm{CVH}$ metrics, and so did the AVR, which was consistent with the previously published results [15]. However, this study only focused on retinal microvascular abnormalities, but RNFL thickness change as another morphological marker was not included. RNFL thickness thinning is an almost qualitative marker of abnormality because it usually does not occur in normal eyes [35]. Retinal microvascular abnormalities, however, show a marked inter-individual variability within the normal population and only a gradual transition from a normal status to a pathological status. So, we examined the relationship between RNFL thickness and ideal CVH metrics in our study. However, the thickness of RNFL showed no significant differences between the participants with different number of ideal CVH metrics. The negative results may imply that the change in RNFL thickness may be more associated with some age-related disorders or small vascular diseases, but not with the atherosclerotic diseases. The retinal arteries and veins, 
inversely, were more associated with atherosclerosis, which was significantly influenced by ideal $\mathrm{CVH}$ metrics.

Potential limitations of our study should be discussed. Firstly, our study was a cross-sectional investigation, and the study design did not allow us to draw longitudinal conclusions on a causal relationship between retinal abnormalities and ideal $\mathrm{CVH}$ metrics. Secondly, fundus photographs were taken but no other more detailed ocular characteristics questionnaires, and examination or secondary analysis of the fundus photography were done in our study. So, we did not discuss whether other retinopathies were associated with ideal $\mathrm{CVH}$ metrics, or whether other retinal diseases and metrics influenced the relationship between the retinal vessels and ideal $\mathrm{CVH}$ metrics. In continuation to our study, further analysis on fundus photography and the relationship between retinal abnormalities and ideal $\mathrm{CVH}$ metrics should be discussed in the future. Thirdly, we did not use validated dietary and physical activity questionnaires, which has been discussed in the previous studies $[8,13]$. However, the included parameters did reflect the status of dietary and physical activity. Fourthly, the APAC study is not a nationally representative sample and our findings may not be generalized directly to other population in China with different educational, economic and cultural backgrounds.

\section{Conclusions}

In conclusion, participants with a larger number of ideal $\mathrm{CVH}$ metrics had a significantly wider CRAE and larger AVR, supporting the importance of ideal health behaviors and factors in the prevention of retinopathy.

\begin{abstract}
Abbreviations
AHA: American Heart Association; AVR: Arterio-venous ratio; BMI: Body mass index; CIMT: Carotid intima-media thickness; CRAE: Central retinal arteriolar equivalents; CRVE: Central retinal venous equivalents; CVD: Cardiovascular diseases; $\mathrm{CVH}$ : Ideal cardiovascular health; DBP: Diastolic blood pressure; ECAS: Extracranial artery stenosis; ICAS: Intracranial artery stenosis; RNFL: Retinal nerve fiber layer; SBP: Systolic blood pressure; SD-OCT: Spectral-domain optical coherence tomography; TCD: Transcranial Doppler
\end{abstract}

\section{Acknowledgments}

We thank all enrolled participants and their relatives.

\section{Funding}

This work was supported by the National Natural Science Foundation of China [Grant No. 81501001] and Beijing Outstanding Talent Training Projects [Grant No. 2014000021469G256].

\section{Availability of data and materials}

The datasets used and/or analyzed during the current study are available from the corresponding author on reasonable request.

\section{Authors' contributions}

Q.Z. and D.W. analyzed, interpreted the data and drafted the manuscript. X.Z.,W.W. and S.W. conceived and designed the research. X.Z. and Q.Z. handled funding and supervision. A.W., Y.L. and S.C. acquired the data. Y.P. and S.Z. made critical revision of the manuscript. All authors read and approved the final manuscript.

\section{Ethics approval and consent to participate}

This study was performed according to the guidelines of Helsinki Declaration and was approved by both the Ethics Committees of the Kailuan General Hospital and Beijing Tiantan Hospital. Written informed consent was obtained from all participants and approved by the above ethics committees.

\section{Consent for publication}

Not applicable

\section{Competing interests}

The authors declare that they have no competing interests.

\section{Publisher's Note}

Springer Nature remains neutral with regard to jurisdictional claims in published maps and institutional affiliations.

\section{Author details \\ 'Department of Neurology, Beijing Tiantan Hospital, Capital Medical University, No.6 Tiantanxili, Dongcheng District, Beijing 100050, China. ${ }^{2}$ China National Clinical Research Center for Neurological Diseases, Beijing, China. ${ }^{3}$ Center of Stroke, Beijing Institute for Brain Disorders, Beijing, China. ${ }^{4}$ Beijing Key Laboratory of Translational Medicine for Cerebrovascular Disease, Beijing, China. ${ }^{5}$ Department of Neurology, The General Hospital of Chinese People's Armed Police Forces, Beijing, China. ${ }^{6}$ Beijing Tongren Eye Center, Beijing Key Laboratory of Ophthalmology and Visual Science, Beijing Tongren Hospital, Capital Medical University, 1 Dong Jiao Min Lane, Beijing 100730, China \\ ${ }^{7}$ Department of Cardiology, Kailuan Hospital, Tangshan 063000, China.}

Received: 2 August 2017 Accepted: 17 September 2018

Published online: 01 October 2018

\section{References}

1. Lloyd-Jones DM, Hong Y, Labarthe D, Mozaffarian D, Appel L, Van Horn L Greenlund K, Daniels S, Nichol G, Tomaselli GF, et al. Defining and setting national goals for cardiovascular health promotion and disease reduction: the American Heart Association's strategic impact goal through 2020 and beyond. Circulation. 2010;121(4):586-613.

2. Bambs C, Reis SE. Embracing primordial prevention for ideal cardiovascular health. Futur Cardiol. 2011;7(4):447-50.

3. Folsom AR, Yatsuya H, Nettleton JA, Lutsey PL, Cushman M, Rosamond WD, Investigators AS. Community prevalence of ideal cardiovascular health, by the American Heart Association definition, and relationship with cardiovascular disease incidence. J Am Coll Cardiol. 2011;57(16):1690-6.

4. Bambs C, Kip KE, Dinga A, Mulukutla SR, Aiyer AN, Reis SE. Low prevalence of "ideal cardiovascular health" in a community-based population: the heart strategies concentrating on risk evaluation (heart SCORE) study. Circulation. 2011;123(8):850-7.

5. Dong C, Rundek T, Wright CB, Anwar Z, Elkind MS, Sacco RL. Ideal cardiovascular health predicts lower risks of myocardial infarction, stroke, and vascular death across whites, blacks, and hispanics: the northern Manhattan study. Circulation. 2012;125(24):2975-84

6. Shay CM, Ning H, Allen NB, Carnethon MR, Chiuve SE, Greenlund KJ, Daviglus ML, Lloyd-Jones DM. Status of cardiovascular health in US adults: prevalence estimates from the National Health and nutrition examination surveys (NHANES) 2003-2008. Circulation. 2012;125(1):45-56.

7. Wu S, Huang Z, Yang X, Zhou Y, Wang A, Chen L, Zhao H, Ruan C, Wu Y, Xin A, et al. Prevalence of ideal cardiovascular health and its relationship with the 4-year cardiovascular events in a northern Chinese industrial city. Circ Cardiovasc Qual Outcomes. 2012;5(4):487-93.

8. Zhang Q, Zhou Y, Gao X, Wang C, Zhang S, Wang A, Li N, Bian L, Wu J, Jia $\mathrm{Q}$, et al. Ideal cardiovascular health metrics and the risks of ischemic and intracerebral hemorrhagic stroke. Stroke. 2013;44(9):2451-6.

9. Kulshreshtha A, Goyal A, Veledar E, McClellan W, Judd S, Eufinger SC, Bremner JD, Goldberg J, Vaccarino V. Association between ideal cardiovascular health and carotid intima-media thickness: a twin study. J Am Heart Assoc. 2014;3(1):e000282.

10. Sturlaugsdottir R, Aspelund T, Bjornsdottir G, Sigurdsson S, Eiriksdottir G, Imai CM, Garcia M, Launer $\sqcup$, Harris TB, Gudnason V. Carotid atherosclerosis and cardiovascular health metrics in old subjects from the AGES-Reykjavik study. Atherosclerosis. 2015;242(1):65-70. 
11. Pahkala K, Hietalampi $H$, Laitinen TT, Viikari JS, Ronnemaa T, Niinikoski $H$, Lagstrom H, Talvia S, Jula A, Heinonen OJ, et al. Ideal cardiovascular health in adolescence: effect of lifestyle intervention and association with vascular intima-media thickness and elasticity (the special Turku coronary risk factor intervention project for children [STRIP] study). Circulation. 2013;127(21): 2088-96.

12. Crichton GE, Elias MF, Robbins MA. Cardiovascular health and arterial stiffness: the Maine-Syracuse longitudinal study. J Hum Hypertens. 2014; 28(7):444-9.

13. Zhang Q, Zhang S, Wang C, Gao X, Zhou Y, Zhou H, Wang A, Wu J, Bian L, Wu $S$, et al. Ideal cardiovascular health metrics on the prevalence of asymptomatic intracranial artery stenosis: a cross-sectional study. PLoS One. 2013;8(3):e58923.

14. Hao Z, Zhang Y, Li Y, Zhao J, Zhou Y, Qiu J, Zhao R, Hu J. The association between ideal cardiovascular health metrics and extracranial carotid artery stenosis in a northern Chinese population: a cross-sectional study. Sci Rep. 2016;6:31720.

15. Ogagarue ER, Lutsey PL, Klein R, Klein BE, Folsom AR. Association of ideal cardiovascular health metrics and retinal microvascular findings: the atherosclerosis risk in communities study. J Am Heart Assoc. 2013;2(6): e000430.

16. Wang D, Li Y, Wang C, Xu L, You QS, Wang YX, Zhao L, Wei WB, Zhao X, Jonas JB. Localized retinal nerve fiber layer defects and stroke. Stroke. 2014; 45(6):1651-6.

17. Zhou Y, Li Y, Xu L, Xu J, Wang A, Gao X, Wu S, Wei WB, Zhao X, Jonas JB. Asymptomatic polyvascular abnormalities in community (APAC) study in China: objectives, design and baseline characteristics. PLoS One. 2013;8(12): e84685.

18. Liu X, Cui L, Wang A, Wang X, Song Q, Li S, Shi J, Zhao X, Chen S, Du X, et al. Cumulative exposure to ideal cardiovascular health and incident diabetes in a Chinese population: the Kailuan study. J Am Heart Assoc. 2016;5(9):e004132.

19. Chen S, Li W, Jin C, Vaidya A, Gao J, Yang H, Wu S, Gao X. Resting heart rate trajectory pattern predicts arterial stiffness in a community-based Chinese cohort. Arterioscler Thromb Vasc Biol. 2017;37(2):359-64.

20. Wong TY, Klein R, Nieto FJ, Klein BE, Sharrett AR, Meuer SM, Hubbard LD, Tielsch JM. Retinal microvascular abnormalities and 10-year cardiovascular mortality: a population-based case-control study. Ophthalmology. 2003; 110(5):933-40.

21. Witt N, Wong TY, Hughes AD, Chaturvedi N, Klein BE, Evans R, McNamara M, Thom SA, Klein R. Abnormalities of retinal microvascular structure and risk of mortality from ischemic heart disease and stroke. Hypertension. 2006; 47(5):975-81.

22. Cooper LS, Wong TY, Klein R, Sharrett AR, Bryan RN, Hubbard LD, Couper DJ, Heiss G, Sorlie PD. Retinal microvascular abnormalities and MRI-defined subclinical cerebral infarction: the atherosclerosis risk in communities study. Stroke. 2006;37(1):82-6

23. Lindley RI, Wang JJ, Wong MC, Mitchell P, Liew G, Hand P, Wardlaw J, De Silva DA, Baker M, Rochtchina $E_{1}$ et al. Retinal microvasculature in acute lacunar stroke: a cross-sectional study. Lancet Neurol. 2009;8(7):628-34.

24. Ikram MK, De Jong FJ, Van Dijk EJ, Prins ND, Hofman A, Breteler MM, De Jong PT. Retinal vessel diameters and cerebral small vessel disease: the Rotterdam scan study. Brain. 2006;129(Pt 1):182-8.

25. Kim M, Park KH, Kwon JW, Jeoung JW, Kim TW, Kim DM. Retinal nerve fiber layer defect and cerebral small vessel disease. Invest Ophthalmol Vis Sci. 2011;52(9):6882-6.

26. Xanthakis V, Enserro DM, Murabito JM, Polak JF, Wollert KC, Januzzi JL, Wang TJ, Tofler G, Vasan RS. Ideal cardiovascular health: associations with biomarkers and subclinical disease and impact on incidence of cardiovascular disease in the Framingham offspring study. Circulation. 2014;130(19):1676-83.

27. Yang JY, Yang X, Li Y, Xu J, Zhou Y, Wang AX, Gao X, Xu L, Wu SL, Wei WB, et al. Carotid atherosclerosis, cerebrospinal fluid pressure, and retinal vessel diameters: the asymptomatic Polyvascular abnormalities in community study. PLoS One. 2016;11(12):e0166993.

28. Leung H, Wang JJ, Rochtchina E, Tan AG, Wong TY, Klein R, Hubbard LD, Mitchell P. Relationships between age, blood pressure, and retinal vessel diameters in an older population. Invest Ophthalmol Vis Sci. 2003;44(7):2900-4

29. Sharrett AR, Hubbard LD, Cooper LS, Sorlie PD, Brothers RJ, Nieto FJ, Pinsky JL, Klein R. Retinal arteriolar diameters and elevated blood pressure: the atherosclerosis risk in communities study. Am J Epidemiol. 1999;150(3):263-70.
30. Kawasaki R, Cheung N, Wang JJ, Klein R, Klein BE, Cotch MF, Sharrett AR, Shea S, Islam FA, Wong TY. Retinal vessel diameters and risk of hypertension: the multiethnic study of atherosclerosis. J Hypertens. 2009;27(12):2386-93.

31. Xu L, Zhou JQ, Wang S, Wang YX, You QS, Yang H, Zhang YQ, Wu MY, Lu YF, Fan YY, et al. Localized retinal nerve fiber layer defects and arterial hypertension. Am J Hypertens. 2013;26(4):511-7.

32. Avery CL, Kucharska-Newton A, Monda KL, Richey Sharrett A, Mosley TH, Klein BE, Cotch MF, Wong TY, Klein R. Impact of long-term measures of glucose and blood pressure on the retinal microvasculature. Atherosclerosis. 2012;225(2):412-7.

33. Zhao Y, Yang K, Wang F, Liang Y, Peng Y, Shen R, Wong T, Wang N. Associations between metabolic syndrome and syndrome components and retinal microvascular signs in a rural Chinese population: the Handan eye study. Graefes Arch Clin Exp Ophthalmol. 2012;250(12):1755-63.

34. Klein R, Sharrett AR, Klein BE, Chambless LE, Cooper LS, Hubbard LD, Evans G. Are retinal arteriolar abnormalities related to atherosclerosis?: the atherosclerosis risk in communities study. Arterioscler Thromb Vasc Biol. 2000;20(6):1644-50.

35. Jonas JB, Dichtl A. Evaluation of the retinal nerve fiber layer. Surv Ophthalmol. 1996;40(5):369-78

\section{Ready to submit your research? Choose BMC and benefit from:}

- fast, convenient online submission

- thorough peer review by experienced researchers in your field

- rapid publication on acceptance

- support for research data, including large and complex data types

- gold Open Access which fosters wider collaboration and increased citations

- maximum visibility for your research: over $100 \mathrm{M}$ website views per year

At $\mathrm{BMC}$, research is always in progress.

Learn more biomedcentral.com/submissions 